\title{
The study of the reactivity of derivatives of hydroxycinnamic alcohol as model compounds of lignin
}

\author{
(C) Oleg K. Karimov, ${ }^{1+}$ Galina Yu. Kolchina, ${ }^{2}$ and Eldar M. Movsumzade ${ }^{3 *}$ \\ ${ }^{1}$ Department of General Chemical Technology. Ufa State Petroleum Technological University, Branch \\ of the University in Sterlitamak. Oktyabrya Ave., 2. Sterlitamak, 453118. Bashkortostan Republic. Russia. \\ Phone: +7 (3473) 24-25-12. E-mail: karimov.oleg@gmail.com \\ ${ }^{2}$ Department of Chemistry and Chemical Technology. Bashkir State University, Branch of the University \\ in Sterlitamak. Lenina St., 47. Sterlitamak, 453103. Bashkortostan Republic. Russia. \\ Phone: +7 (3473)33-98-50.E-mail: kolchina.GYu@mail.ru \\ ${ }^{3}$ Department of General, Analytical and Applied Chemistry. Ufa State Petroleum Technological \\ University. Kosmonavtov St., 1. Ufa, 450062. Bashkortostan Republic. Russia. \\ Phone:+7(3472) 42-03-70.E-mail:eldarmm@yahoo.com
}

Keywords: lignin, coumaric alcohol, coniferyl alcohol, synapol alcohol, reactivity.

\begin{abstract}
In the framework of method of the B3LYP hybrid density functional and the restricted Hartree-Fock method in the basis of 6-311 (d, p), quantum-chemical calculations of model compounds of lignin, i.e. derivatives of $p$-hydroxycinnamic alcohol were carried out. The structures and reactivity of coumaric, coniferyl and synapol alcohols were studied. The structural units of lignin contain hydroxyl groups which can be in the plane of benzene ring but can be turned up to $90^{\circ}$ with respect to this plane. In the case of methoxy groups which are also present in coniferol and synapol alcohols, the methyl group is turned to $90^{\circ}$ with respect to the plane of ring, as the most favorable conformation. Moreover, these compounds contain $\pi, \pi$-conjugations of the aromatic ring with an aliphatic fragment of molecule that affects the geometric characteristics of the molecule. For coumaric and coniferyl alcohols, the $\mathrm{C}_{\mathrm{ap}}-\mathrm{C}_{\alpha}$ bond length is $1.47 \AA$. A slight deformation of valence angles for coumaric and synapol alcohols equal to $118.94^{\circ}$ and $117.72^{\circ}$ respectively instead of $120^{\circ}$ at $\mathrm{sp}^{2}$ hybridization indicates the availability of conjugation. The use of a charge as a descriptor of attack selectivity of nucleophilic and electrophilic particles allows us to analized of the reactivity of these acids are given. It is found that the electronic structure of lignin is determined primarily by the charge distribution in its structural phenylpropane unit. In the molecules of all model compounds of lignin, the center for nucleophilic attack is the carbon of aromatic ring (E-ring) with a hydroxyl group, and in the molecule of synapol alcohol, this center is also the carbon of the aromatic ring (E-ring) with a methoxy group. In all three compounds, a center with an increased electron density appears on the $\mathrm{C}_{\beta}$ carbon atom.
\end{abstract}

\section{References}

[1] A.P. Karmanov, and L.S. Kocheva. Characteristic of polymer properties and structure of Pepper's lignin macromolecules in dimethylformamide. Butlerov Communications. 2017. Vol.49. No.1. P.84-90. DOI: 10.37952/ROI-jbc-02/17-49-1-84

[2] A.P. Karmanov, S.M. Poleschikov, and L.S. Kocheva. Theoretical and experimental simulation of lignin biosynthesis. Butlerov Communications. 2015. Vol.41. No.3. P.147-151. DOI: 10.37952/ROI-jbc-02/1541-3-147

[3] C. Heiter, D.R. Dimmel, J.A. Schmidt. Lignin and Lignans. Advances in Chemistry. New York: CRC Press. 2010. 636p.

[4] S.M. Shevchenko. Theoretical approaches to lignin chemistry. Croatica chemical acta. 1994. No.67(1). P.95-124.

[5] T.J. Elder, S.D. Worley. The application of molecular orbital calculations to wood chemistry. Wood Sci. Technol. 1984. Vol.18. P.307-315.

[6] C. Martinez, J.L. Rivera, R. Herrera, J.L. Rico, N. Flores, J.G. Rutiaga, P. Lopez. Evaluation of the chemical reactivity in ligninprecursors using the Fukui function. J Mol Model. 2008. Vol.14. P.77-81. 
[7] A.A. Funk and V.V. Korenek. Indices of electrophilicity of monolignols - model compounds of lignin. Chemistry of plant materials. 2008. No.3. P.39-44. (russian)

[8] G.Yu. Kolchina, N.Ch. Movsum-zade, A.Yu. Bakhtina and E.M. Movsumzade. Overview of the main achievements of mankind in quantum chemistry. Oil \& gas chemistry. 2016. No.1. P.51-60. (russian)

[9] G.Yu. Kolchina, N.Ch. Movsum-zade, A.Yu. Bakhtina and E.M. Movsumzade. Origin and chronology of the stages development quantum chemistry. History and pedagogy of natural science. 2015. No.4. P.3443. (russian)

[10] G.Yu. Alexandrova, N.Ch. Movsum-zade and R.I. Makhmutova. Mathematical design of quantum chemical calculations. History of science and technology. 2011. Special issue 2. No.8. P.14-21. (russian)

[11] G.Yu. Alexandrova, N.Ch. Movsum-zade, R.I. Makhmutova and D.A. Chuvashov. Stages of nucleation and formation of quantum chemical calculations. History and pedagogy of natural science. 2011. No.1. P.42-49. (russian)

[12] Alex A. Granovsky, Firefly version 7.1.G, http://classic.chem.msu.su/gran/firefly/index.html.

[13] M.W. Schmidt, K.K. Baldridge, J.A. Boatz, S.T. Elbert, M.S. Gordon, J.H. Jensen, S. Koseki, N. Matsunaga, K.A. Nguyen, S. Su, T.L. Windus, M. Dupuis, J.A. Montgomery. General Atomic and Molecular Electronic Structure System. Comput.Chem. Eng. 1993. No.14. P.1347-1363.

[14] W. Yang, W. Mortier. The use of global and local molecular parameters for the analysis of the gasphase basicity of amines. J. Amer. Chem. Soc. 1986. Vol.108. P.5708-5711.

[15] J. Cioslowski, M. Martinov, S.T. Mixon. Atomic Fukui indexes from the topological theory of atoms in molecules applied to Hartree-Fock and correlated electron densities. J. Phys. Chem. 1993. Vol.97. P.10948-10951.

[16] C. Lee, W. Yang, R. Parr. Local softness and chemical reactivity in the molecules CO, SCN- and $\mathrm{H}_{2}$ CO. J. Mol. Struct. (Theochem). 1988. Vol.163. P.305-313. 